\title{
The reliability control of the existing buildings
}

\author{
Alexander Frolov ${ }^{1}$, Irina Frolova ${ }^{1}$, and Olga Kotkova ${ }^{1, *}$ \\ ${ }^{1}$ Samara State Technical University, Institute of Architecture and Civil Engineering, \\ Molodogvardeyskaya str. 194, 443001 Samara, Russia
}

\begin{abstract}
Change control of enclosure structures state includes several tasks depending on a structural concept. To test the performance of thermal protective functions the distribution uniformity of the thermal field, possible losses or protection quality are controlled. Defects can emerge in bearing wall constructions, such as the material structure violation and it reduces the walls safety. Cracks, loose layer, loss of individual elements, the disclosure of stitches and so forth also lead to the change of the thermal field. Thermovision research based on the developed methodology helps to monitor emerging defects in the materials of buildings wall structure. Most of the detected thermal protection defects are not critical for the bearing capacity of building structures in general, but they are important for the microclimate of separate rooms.
\end{abstract}

\section{Introduction}

Vertical walls of the building can be load bearing and non-load bearing. During the operation they obtain various defects affecting their safety or just reducing operational characteristics. Defects can be visible and hidden.

Heat monitoring method allows us to control the thermal protection quality of singlelayer and multi-layer structures and their connections. It also helps to detect under natural conditions sections of walls slated for repair and with hidden defects. There are two ways of applying this method: assessment of thermal insulation characteristics of the enclosing structures and defective zones establishment of wall constructions [1].

\section{Heat Monitoring Implementation}

Thermal insulation control method is performed by using thermographic camera. It is based on remote measurement of the surface enclosing structure temperature field. Temperature anomalies are visualized on the defective areas as areas of high temperatures.

Temperature fields of enclosing structures are obtained in the form of false color image accompanied by the appropriate scale. The color boundaries correspond to different temperatures. When there is a monochrome image the temperature gradations are determined by the image brightness that is set by the temperature scale that accompanies the image. It is recommended to carry out heat monitoring in spring and autumn when the

\footnotetext{
${ }^{*}$ Corresponding author: kotkovaon@yandex.ru
} 
temperature difference between the outside and indoor air is equal to $10-15^{\circ} \mathrm{C}$. The higher the differential temperature, the more accurate analyses.

It is acceptable to carry out thermovision measurements when the differential temperature between the outdoor and indoor air exceeds $\Delta \mathrm{t}_{\min }{ }^{\circ} \mathrm{C}$ :

$$
\Delta t_{\min }=2 \Delta \theta R_{0}{ }^{n} \cdot(\alpha \cdot \tau) /(1-\tau)
$$

$\Delta \theta$ - temperature sensitivity limit, ${ }^{\circ} \mathrm{C}$ (in this case $\Delta \theta=2{ }^{\circ} \mathrm{C}$ );

$\alpha$ - heat-transfer coefficient accepted for face of walls depending on wind speed:

$1 ; 3 ; 6 \mathrm{~m} / \mathrm{s}-11 ; 20 ; 30 \mathrm{~W} /{ }^{\circ} \mathrm{C} \cdot \mathrm{m}^{2}$, correspondingly;

$R_{0}{ }^{n}$ - design value of heat transmission resistance, ${ }^{\circ} \mathrm{C}$;

$\tau$-relative resistance to heat transfer of the investigated fence zone.

In practice the deferential of indoor and outdoor air not less than $10-15^{\circ} \mathrm{C}$ is sufficient.

The monitoring, according to [2], is divided into three types. The first one provides the examination of the object to form the overall characteristics and to identify areas to be further thermographed. The second one represents an overview thermography of wall surfaces including large-scale overview thermography. Based on these two types of inspection fiducial or base areas and shooting points for the detailed thermography are selected. The third type is the detailed thermography (if necessary) - depending on the task.

The results of the review and detailed thermography are divided into qualitative and quantitative. Qualitative are limited to information contained in thermograms and used for surveys aimed at identifying defects without quantitative calculation of local heat transfer resistance. Quantitative results of thermography can be used in further calculations for the recovery of enclosing structures heat-shielding properties.

In order to obtain qualitative results one or two fiducial (base) areas are chosen in the thermogram: temperature difference there exceeded several times the accuracy of the temperature measurement by non-contact method and the thermographic camera sensitivity.

When performing the first stage of the object inspection with a thermographic camera the fiducial point is not required. The inspection is carried out to create a common quality characteristic and the identification of heat loss defects.

During the inspection the base area is determined (marked on the design by any means); its linear dimensions should exceed two thicknesses. The area is selected in the temperature zone close to the minimum at the surface.

Before and after thermography humidity and temperature of outdoor and indoor air are measured. During the survey the parameter checkout is carried out in 15-30 minutes. Additionally, the wind speed is measured at the external survey. If the thermogram is created from individual sections then in order to obtain a single image, thermography is produced with an overlap of each adjacent section by $10 \%$.

It is recommended to expose corner sections and joints to additional thermography. The surface survey should not be in the irradiation zone within 12 hours prior to measurement. The survey points are selected so that the surface of the object measurement is in direct line of sight at an observation angle of not more than $60{ }^{\circ} \mathrm{C}$.

\section{The Results Processing of the Survey}

The aim of the thermogram processing is the transition from radiation temperatures, recorded by the thermographic camera, to actual temperatures of the surface. Processing is carried out by software of the used device. It is not required to conduct any additional research using a computer if the obtained temperature values at the base areas coincide with the temperatures measured by the contact method. 
The thermogram processing is not carried out if the surveys are conducted in a simplified form at the qualitative level, for example, to monitor the condition of enclosure structures. In this case the defects with different temperatures are defined in order to make a decision on the enclosure defectiveness in terms of thermal protection. In this way, the internal structures defects are detected.

At the qualitative level the thermography is carried out under the quality monitoring of thermal insulation implementation. In this case, the heat loss is calculated. Based on the data that characterize the thermal protection quality of the enclosure structures, we can decide on carrying out additional works to reduce the heat loss of the building [3].

When interpreting the thermograms we should pay attention to the following aspects:

1. On the thermogram taken indoors, the interest area is with a lower temperature. At the color palette these are blue, purple and black, accordingly. As the thermography is a qualitative evaluation method then it is necessary to pay attention to the irregularity of temperature distribution at the areas where, according to the technical design, there are no reasons for the anomaly.

2. On the thermogram taken outdoors, the situation is reversed and defects are considered to be the areas with high temperatures, usually white, yellow and red colors.

3. The temperature value plays a role in assessing the risk of condensing - dew point, which is calculated from the temperature and relative humidity. Also for the condensate formation on the surface, the lack of air exchange is required. It should be taken into consideration that the error of the thermographic camera is $+/-2^{\circ} \mathrm{C}$.

Figure 1 shows the thermogram of enclosure structure areas with defects.

a)

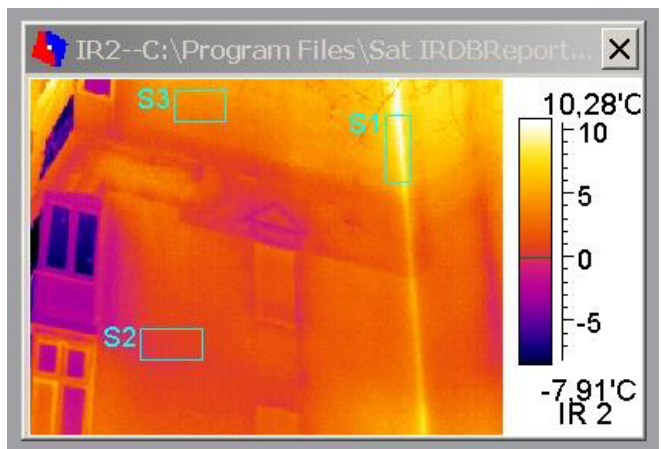

b)

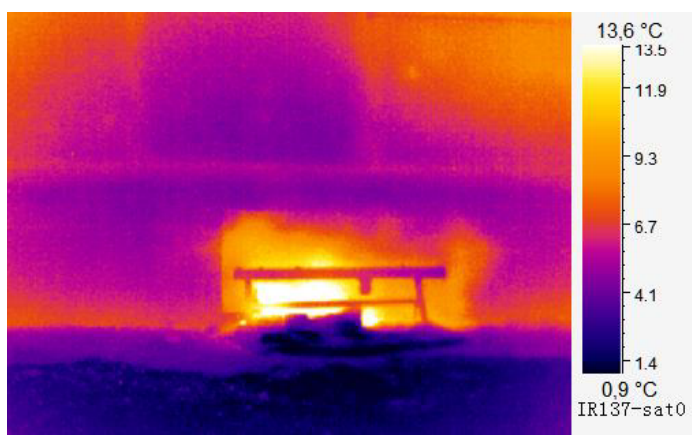

Fig. 1. The thermogram of enclosure structure areas with defects: a - through crack in the wall; $b$ - steeping the wall basement with surface deterioration. 


\section{Conclusion}

Most of the detected thermal protection defects are not critical for the bearing capacity of building structures in general but they are important for the microclimate of separate rooms [4-7]. The low level of enclosure structures thermal protection and local thermal protection defects are the reason for comfort criteria violations [8-10]. As shown above, heat monitoring helps to detect and remove defects of buildings thermal protection [11].

\section{References}

1. V.D. Tulukanov, News Bulletin "Energosvet”. 3rd (3) Edition, 14-17 (2009)

2. GOST P 54852-2011. Thermal insulation quality control method of walling. M.: Russian Ministry of Regional Development (2011)

3. Design and Construction Specifications 50.13330.2012. Buildings Heat Insulation. SNiP revised edition 23-02-2003, M.: Russian Ministry of Regional Development (2013)

4. GOST 31937-2011. Buildings and structures. Examination and monitoring rules of technical condition, M.: Russian Ministry of Regional Development (2011)

5. M.V. Yakovleva, E.A. Frolov, A.E. Frolov, Science and Technosphere safety: collection of articles, 394-398 (2015)

6. M.V. Yakovleva, E.A. Frolov, Traditions and innovations in construction and architecture: proceedings of the 66th All-Russian science technical conference according to the R\&D, (2009)

7. M.V. Yakovleva, E.A. Frolov, Traditions and innovations in construction and architecture: Proceedings of the 68th All-Russian science technical conference according to the R\&D,m935-936 (2011)

8. T.E. Gordeeva, Science Vector of Togliatti State University 1(23), 104-107 (2013)

9. E.A. Frolov, A.E. Frolov, Traditions and innovations in construction and architecture: Proceedings of the 71st All-Russian science technical conference according to the R\&D, 913-914 (2014)

10. V.M. Balkin, Traditions and innovations in construction and architecture: Proceedings of the 71st All-Russian science technical conference according to the R\&D, 917-919 (2014)

11. I.G. Frolova, Traditions and innovations in construction and: Proceedings of the 71 st All-Russian science technical conference according to the R\&D, 926-927 (2014) 